\title{
Sustentabilidade empresarial: uma análise das matrizes de materialidade das empresas globais fabricantes de automóveis
}

\author{
Andreia Ribeiro Ayres ${ }^{1}$ \\ Andrea Soares Bonifácio ${ }^{2}$ \\ Luana dos Anjos Silva ${ }^{3}$
}

\section{RESUMO}

A Matriz de Materialidade surge como um elemento do Relatório de Sustentabilidade elaborado a partir das diretrizes da Global Report Initiative - GRI. É apresentada como uma ferramenta importante para construção da estratégia de sustentabilidade das empresas, uma vez que identifica os aspectos dos âmbitos econômico, ambiental e social da sustentabilidade que são mais relevantes para os stakeholders e para a empresa, contribuindo para que ela foque suas ações de sustentabilidade nos aspectos mais relevantes a serem tratados. $\mathrm{O}$ objetivo deste trabalho é identificar o aspecto material mais citado na Matriz de Materialidade das empresas globais fabricantes de automóveis e descrever como as empresas o tem abordado em suas estratégias. Trata-se de uma pesquisa descritiva com abordagem qualitativa. Foram realizadas pesquisas bibliográfica e documental sobre responsabilidade social empresarial, desenvolvimento sustentável e matriz de materialidade. Os resultados mostram que o aspecto mais citado é emissão de Dióxido de Carbono - $\mathrm{CO} 2$ e que as abordagens das empresas para responder as demandas dos stakeholders acerca desse aspecto se dão por toda sua cadeia de valor.

Palavras-chave: Matriz de Materialidade. Gestão de Stakeholder. Responsabilidade Social.

\footnotetext{
${ }^{1}$ Graduada em Ciências Econômicas pela Universidade Federal Rural do Rio de Janeiro - UFRRJ. Mestra e Doutora em Engenharia de Produção, ambos pela Universidade Federal do Rio de Janeiro - UFRJ. É pesquisadora colaboradora do Laboratório de Tecnologia e Desenvolvimento Social da COPPE/UFRJ, e professora do Departamento de Engenharia de Produção da Universidade Federal do Estado do Rio de Janeiro - UNIRIO, RJ, Brasil. E-mail: andreiaayres7@ hotmail.com.

${ }^{2}$ Graduada em Matemática pela Universidade do Estado do Rio de Janeiro - UERJ e também em Economia pela Universidade Federal Fluminense - UFF. Mestra em Informática e Doutora em Engenharia de Produção, ambos pela Universidade Federal do Rio de Janeiro - UFRJ. É professora, pesquisadora e coordenadora Pro Tempore do curso de Engenharia de Produção da Universidade Federal do Estado do Rio de Janeiro - UNIRIO, RJ, Brasil. E-mail: andreabonifacio@uniriotec.br.

${ }^{3}$ Graduada em Engenharia de Produção pela Universidade Federal do Estado do Rio de Janeiro - UNIRIO. É Engenheira de Planejamento na Sum Engenharia, SP, Brasil. E-mail: anjosluanasilva@gmail.com.
} 


\title{
Corporate sustainability: an analysis of the materiality matrices of global automobile manufacturers
}

\begin{abstract}
The Materiality Matrix emerges as an element of Sustainability's Reports that are prepared by Global Report Initiative - GRI guidelines. It is presented as an important tool for company's sustainability strategy elaboration, since it identifies economic, environmental, and social sustainability aspects that are most relevant to stakeholders and companies, contributing to focus its sustainability actions on most relevant aspects to be address. The objective of this work is to identify most cited material aspect in the Materiality Matrix of global automobile manufacturers and describe how companies have approached it in their strategies. This is a descriptive research with a qualitative approach. Bibliographic and documentary researches carried on corporate social responsibility, sustainable development. The results show that the most cited aspect is carbon dioxide - CO2 emissions and that companies' approaches to responding to the stakeholders' demands on this aspect occurs throughout their entire value chain.
\end{abstract}

Keywords: Materiality Matrix. Stakeholder Management. Social Responsibility.

Artigo recebido em: 29/04/2020

Aceito em: 09/06/2020 


\section{INTRODUÇÃ̃O}

A Sustentabilidade dos Negócios tem sido encarada como uma estratégia empresarial para geração de valor que traz benefícios como estímulo à inovação, redução de custos, mitigação de riscos, melhora da reputação e da imagem, entre outros (BM\&FBOVESPA, 2010 apud BENITES; POLO, 2013). Como qualquer área estratégica, é necessário medir e coletar informações sobre seu desempenho, daí a criação de modelos de diretrizes de gestão da sustentabilidade e meios de comunicação desse desempenho para os stakeholders. A junção dessas informações sobre os indicadores de sustentabilidade e documentos, contendo informações sobre os impactos econômicos, ambientais e sociais, é comumente denominada Relatório Socioambiental, Relatório Social Corporativo ou Relatório de Sustentabilidade.

A Matriz de Materialidade surge como um elemento do Relatório de Sustentabilidade elaborado a partir das diretrizes da Global Report Initiative - GRI, com o objetivo de "melhorar a qualidade, o rigor e a aplicabilidade dos relatórios de sustentabilidade" (GRI, 2002, p. 1). Além disso, a Matriz de Materialidade é apresentada como uma ferramenta importante para construção da estratégia de sustentabilidade das empresas, uma vez que identifica os aspectos dos âmbitos econômico, ambiental e social da sustentabilidade que são mais relevantes para os stakeholders e para a empresa. A Matriz de Materialidade foca as ações de sustentabilidade das empresas para os aspectos mais relevantes a serem tratados.

O objetivo geral deste trabalho é identificar o aspecto material mais citado na Matriz de Materialidade das empresas globais fabricantes de automóveis e descrever como as empresas o tem abordado em suas estratégias. Os objetivos específicos são: apresentar os conceitos de Matriz de Materialidade; levantar os aspectos materiais das três dimensões da sustentabilidade - econômica, ambiental e social - das Matrizes de Materialidade que são apresentadas nos Relatórios de Sustentabilidade, referentes ao ano de 2017, das empresas globais fabricantes de automóveis e identificar o aspecto material mais citado nas matrizes e descrever como as empresas o tem abordado.

\section{METODOLOGIA}

Esta pesquisa apresenta uma abordagem qualitativa. Quanto aos objetivos, o trabalho pode ser classificado como uma pesquisa descritiva, uma vez que exige do pesquisador uma série de informações sobre objeto a ser pesquisado e busca relatar os acontecimentos e 
fenômenos de uma determinada realidade (TRIVIÑOS, 1987 apud GERHARDT; SILVEIRA, 2009).

Quanto aos procedimentos, o trabalho é composto por uma pesquisa bibliográfica e documental, pois além de levantar referências teóricas que já foram analisadas e publicadas, também busca fontes mais diversas sem tratamento analítico, como relatórios, documentos oficiais, tabelas estatísticas, relatórios de empresas, entre outros (FONSECA, 2002 apud GERHARDT; SILVEIRA, 2009).

A pergunta norteadora da pesquisa é: qual o aspecto material mais citado nas Matrizes de Materialidade das empresas globais fabricantes de automóveis e quais são as ações que essas empresas estão implementando para responder às demandas dos stakeholders sobre esse aspecto?

A primeira etapa do trabalho consistiu na elaboração da revisão da literatura para apresentar o conceito de Matriz de Materialidade como elemento importante para a Gestão de stakeholders e seu papel como uma ferramenta estratégica. Essa etapa se deu através da busca dos termos corporate social responsibility, corporate social responsibility evolution, responsabilidade social, responsabilidade social empresarial, evolução da responsabilidade social empresarial, sustainable development, corporate sustainability, desenvolvimento sustentável, sustentabilidade empresarial, materiality matrix, matriz de materialidade e materialidade nas bases do Portal de Periódicos da Coordenação de Aperfeiçoamento de Pessoal de Nível Superior - CAPES, ScienceDirect e SciELO e Google Acadêmico. Além disso, percebido que uma publicação discutia conceitos importantes para o presente trabalho, buscava-se as mesmas referências bibliográficas que nortearam a pesquisa do respectivo autor.

A segunda etapa do trabalho se deu com o levantamento dos Relatórios de Sustentabilidade referentes ao ano de 2017 das 10 (dez) empresas globais fabricantes de automóveis com maior valor de marca, também referente ao ano de 2017. Os valores de marca foram obtidos no site da Brand Finance, no relatório Auto \& Tyres 2018. Os Relatórios de Sustentabilidade foram obtidos nos respectivos sites de cada empresa. A escolha de 2017 como ano de referência para o levantamento teve como objetivo tornar esse trabalho o mais recente possível. Em relação ao ano de 2018, o levantamento dos relatórios demonstrou que não houve mudanças relevantes no objeto desse estudo - a Matriz de Materialidade. Entende-se que o período de um ano é curto para que mudanças socioambientais relevantes aconteçam a ponto de mudar a perspectiva dos stakeholders, por 
isso, a recomendação da GRI é que as empresas definam uma periodicidade maior que um ano para a realizar o processo de elaboração da matriz. Já em relação ao ano de 2019, o estudo não seria possível porque das dez empresas do ranking de 2019 da Brand Finance apenas três já disponibilizaram o relatório em seus sites, sendo que duas fazem parte de um mesmo grupo e, nesse caso, o relatório delas é publicado em conjunto.

$\mathrm{Na}$ terceira etapa do trabalho, foram levantados os aspectos materiais das três dimensões da Sustentabilidade e das Matrizes de Materialidade. As empresas Volkswagen, Audi e Porsche fazem parte do Grupo Volkswagen e tem sua performance em sustentabilidade reportada no relatório do Grupo. Logo, dos 10 (dez) relatórios mencionados acima, restaram 8 (oito) para o levantamento dos aspectos materiais das matrizes. Os Grupos Volkswagen, Toyota, Nissan e Mercedes-Benz não apresentaram a Matriz de Materialidade nos seus relatórios.

A quarta e última etapa do trabalho consistiu na identificação do aspecto material mais citado nas Matrizes de Materialidade e na descrição de como as empresas têm abordado esse aspecto. A identificação do aspecto material mais citado se deu a partir da classificação dos aspectos com base no conteúdo da Diretriz G4 - um documento elaborado pela GRI com o objetivo de fornecer diretrizes para elaboração de Relatórios de Sustentabilidade. Aqueles que não se classificavam em nenhum conteúdo foram agrupados por similaridade. As abordagens das empresas foram extraídas do respectivos Relatórios de Sustentabilidade das mesmas.

\section{RESULTADOS E DISCUSSÃO}

\subsection{Matriz de Materialidade na gestão de stakeholders}

A Associação Brasileira de Normas Técnicas (2010, p. 4) define Responsabilidade Social como:

Responsabilidade de uma organização pelos impactos de suas decisões e atividades na sociedade e no meio ambiente, por meio de um comportamento ético e transparente que:

- Contribua para um crescimento sustentável, inclusive a saúde e o bemestar da sociedade;

- Leve em consideração as expectativas das partes interessadas;

- Esteja em conformidade com a legislação aplicável e seja consciente com as normas internacionais de comportamento;

- Esteja integrada em toda a organização e seja praticada em suas relações. 
Para responder às expectativas das partes interessadas em relação às dimensões econômica, social e ambiental da sustentabilidade, as organizações de todo o mundo direcionaram seus esforços para formular modelos de relatórios transparentes de divulgação dessas informações, dentre eles o modelo Diretrizes para Relatórios de Sustentabilidade proposto pela Global Report Initiative - GRI (DIAS; SIQUEIRA; ROSSI, 2006).

Além dos relatórios de sustentabilidade no padrão GRI, existem três outros tipos de relatórios que comunicam o desempenho da sustentabilidade da empresa aos seus stakeholders: os Relatórios Sociais (originados na década de 1970), os Relatórios Ambientais (originados no final da década de 1980) e os Relatórios Anuais (originados na metade da década de 1999 até hoje) (DAUB, 2007 apud CAMPOS et al., 2013).

Contudo, as empresas têm se tornado cada vez mais adeptas aos padrões de publicação de relatórios de sustentabilidade dos padrões da GRI (MARIMON et al., 2012 apud CAVATTI, 2014) e é frequente que acionistas e investidores busquem respaldo nesses relatórios para tomar suas decisões de compra e venda de ações (BASSETTO, 2010 apud CAMPOS et al., 2013).

A GRI foi fundada em Boston, nos EUA, em 1997, pela Coalizão por Economias Ambientalmente Responsáveis - CERES e pelo Programa das Nações Unidas para o Meio Ambiente - PNUMA e está sediada em Amsterdã. Ela tem por objetivo "melhorar a qualidade, o rigor e a aplicabilidade dos relatórios de sustentabilidade” (GRI, 2002, p. 1).

Segundo a GRI (2002, p. 4), os relatórios de sustentabilidade são importantes porque:

Cada vez mais, as empresas enfatizam suas relações com os parceiros externos - consumidores, investidores, grupos comunitários - como uma das chaves do sucesso empresarial. Transparência e diálogo aberto sobre sustentabilidade e desempenho ajudam a reforçar essas parcerias e criar confiança.

Desde os anos 2000, quando foi lançada a primeira versão das Diretrizes, a estrutura de elaboração de relatórios passou por evoluções significativas. O Quadro 1 (a seguir) mostra essa evolução. 
Quadro 1: Linha do tempo com versões dos indicadores da GRI

\begin{tabular}{|c|c|l|}
\hline Versão & Ano & \multicolumn{1}{c|}{ Descrição simplificada } \\
\hline G1 & 2000 & $\begin{array}{l}\text { Fortes traços da contabilidade financeira adaptada ao desempenho } \\
\text { econômico, social e ambiental. }\end{array}$ \\
\hline G2 & 2002 & $\begin{array}{l}\text { Melhoria no rigor e na qualidade. Foram inclusos princípios, como } \\
\text { transparência, abrangência, auditabilidade, relevância, clareza e } \\
\text { cronogramas. }\end{array}$ \\
\hline G3 & 2006 & $\begin{array}{l}\text { As modificações na estratégia, perfil, abordagem de gestão e nos } \\
\text { indicadores de desempenho da empresa. }\end{array}$ \\
\hline G3.1 & 2011 & $\begin{array}{l}\text { Discussão e esclarecimento no modo de definição do conteúdo do } \\
\text { relatório. Orientação sobre os impactos da comunidade local, } \\
\text { direitos humanos gênero. }\end{array}$ \\
\hline G4 & 2013 & $\begin{array}{l}\text { Ênfase na materialidade para fornecimento de informações que } \\
\text { reflitam seus impactos econômicos, ambientais e sociais, com base } \\
\text { no relacionamento do público interno e de seus stakeholders. }\end{array}$ \\
\hline
\end{tabular}

Fonte: Adaptado de Jones et al. (2016a) apud Carpejani, Pinheiro de Lima e Machado (2017, p. 3).

O relatório de sustentabilidade com ênfase na materialidade apresentada pela Diretriz G4 visa torná-los mais relevantes, confiáveis e fáceis de serem interpretados (GRI, 2013; GRI, 2016). Jones et al. (2016a) apud Carpejani, Pinheiro de Lima e Machado (2017) consideram que, além da credibilidade, a ênfase também contribui para o aumento da qualidade dos relatórios.

O conceito natural de materialidade emergiu na área financeira pelo levantamento das questões contábeis que preocupavam os investidores, como os processos de auditoria (WHITEHEAD, 2016 apud CARPEJANI; PINHEIRO DE LIMA; MACHADO, 2017). Na literatura, a materialidade no contexto da sustentabilidade se apresenta de duas formas que se relacionam:

- Como um dos três princípios da AA1000 Accountability Principles Standard que faz parte da AA1000 Stakeholder Engagement Standard (ACCOUNTABILITY, 2008) e;

- Como um processo de identificação e priorização dos aspectos relevantes para os negócios e seus stakeholders, ou ainda, "o limiar em que os aspectos da sustentabilidade se tornam suficientemente importantes para serem tratados pela empresa" (GRI, 2013; GRI, 2016, p. 8).

Essa relação pode ser identificada no texto da AA1000 Accountability Principles Standard que explica que a empresa segue o princípio da materialidade na gestão de stakeholders quando, além de outros requisitos, estabelece um processo de definição da sua 
materialidade aplicado a todos os níveis da empresa, integrado e constante. Uma questão só é material para a empresa quando influencia decisões, ações e desempenho próprio ou dos seus stakeholders (ACCOUNTABILITY, 2008). A condição das empresas de se responsabilizarem pelas suas decisões e atividades e prestarem contas aos seus stakeholders é chamada de accountability e é defendida pela AccountAbility (2008), pois:

\begin{abstract}
Obriga uma organização a envolver as partes interessadas na identificação, compreensão e resposta a questões e preocupações de sustentabilidade e a relatar, explicar e responder às partes interessadas por decisões, ações e desempenho. Inclui a maneira pela qual uma organização governa, define a estratégia e gerencia o desempenho (ACCOUNTABILITY, 2008).
\end{abstract}

Portanto, o processo da materialidade contribui para a gestão de stakeholders e elaboração de relatórios de sustentabilidade em um nível altamente estratégico. Além de auxiliar na elaboração dos relatórios, também "aborda a estratégia geral da empresa, gerenciamento de riscos, relacionamentos, comunicações e até mesmo o design de produtos e serviços com impactos de sustentabilidade em mente" (GRI, 2016, p. 9). A KPMG (2014, p. 3), corrobora essa afirmação ao dizer que "a avaliação da materialidade deve ser usada como uma ferramenta estratégica de negócios”.

Em síntese, o macroprocesso da materialidade apresentado pela GRI possui quatro etapas e se inicia com a identificação dos aspectos materiais e seus limites, com base nos impactos das atividades, produtos, serviços e relacionamentos da empresa. Em seguida, temse a priorização desses aspectos com base na avaliação dos tópicos, de acordo com a influência dos tópicos nas opiniões e decisões dos stakeholders e a relevância dos impactos econômico, ambiental e social. Essa priorização gera a matriz de materialidade, conforme exemplificado na Figura 1. A terceira etapa é a validação desses aspectos. A quarta e última etapa é a revisão dos aspectos do relatório e a consideração dos feedbacks dos stakeholders acerca das informações publicadas. O macroprocesso pode ser observado na Figura 2.

O processo da materialidade deve ser "sistemático, documentado, replicável e revisado de forma consistente em cada período de elaboração do relatório" (GRI, 2016, p. 9). Segundo a GRI (2016, p. 11), "a metodologia aplicada em cada uma das etapas varia por organização" e a consequência disso é o surgimento de matrizes de materialidade diversas. Na sua forma mais comum, o eixo horizontal representa a significância/relevância dos impactos econômico, ambiental e social para a empresa e o eixo vertical representa a influência na opinião e decisão dos stakeholders (BELLANTUONO; PONTRANDOLFO; SCOZZI, 2016). 
A Figura 1 ilustra a priorização dos aspectos a partir do exemplo da Matriz de Materialidade da Companhia Energética de Minas Gerais (2019), os aspectos abaixo da curva têm menor relevância e os aspectos acima da curva têm maior relevância.

Figura 1: Representação visual da priorização dos aspectos

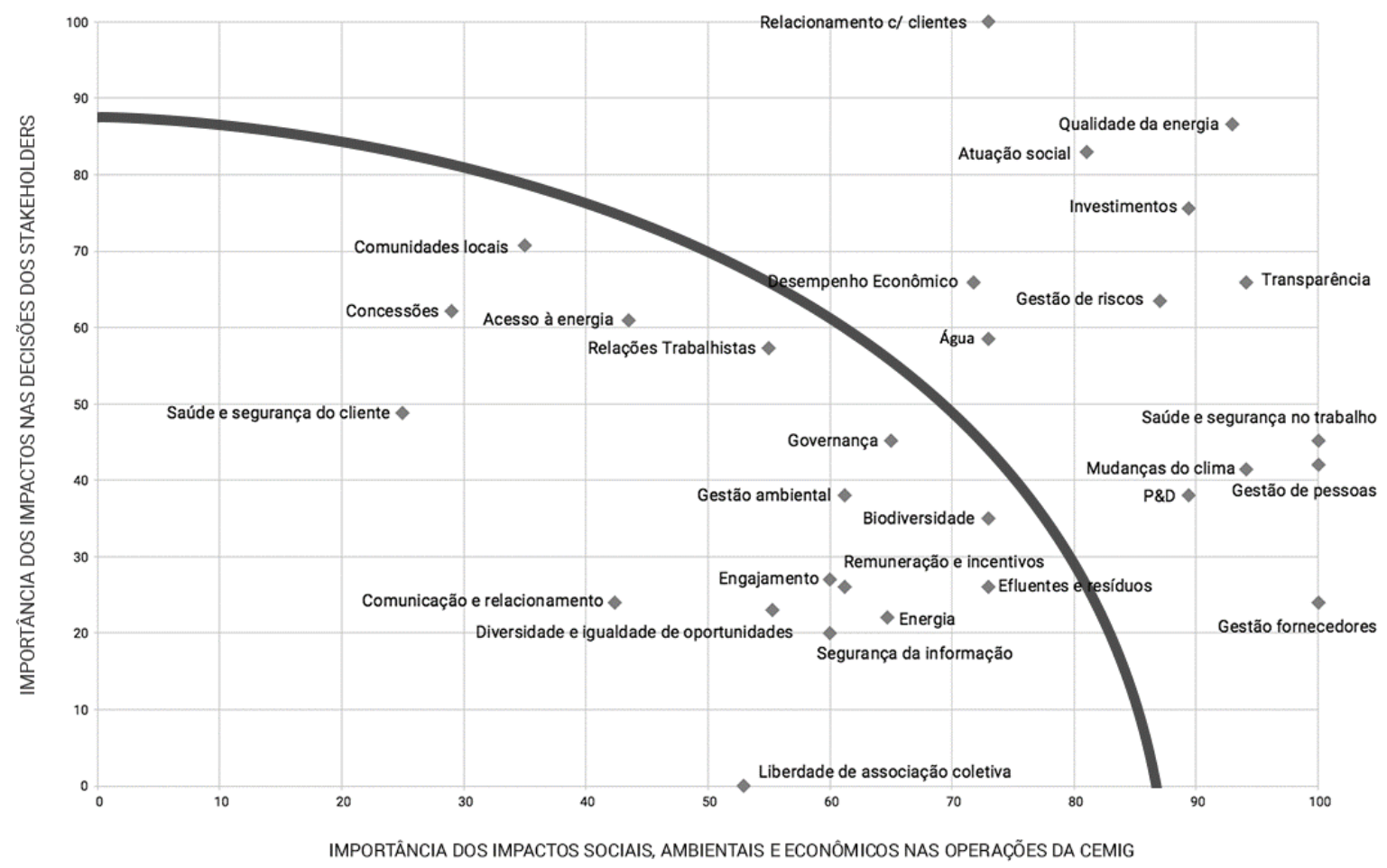

Fonte: Companhia Energética de Minas Gerais - CEMIG (2019).

Spitzeck, Árabe e Pereira (2015), no Guia How-To Matriz de Materialidade, explicam que a identificação dos aspectos materiais pode ser potencializada com um benchmarking dos relatórios de sustentabilidade das empresas do mesmo setor e por uma análise de mídia positiva/negativa e sua relação com os tópicos materiais. Na análise da significância dos impactos, a empresa deve levar em consideração a alavancagem dos seus valores tangíveis (melhorar a margem, melhorar a avaliação e aumentar o lucro) e intangíveis (valor da marca, gestão de riscos e gestão de stakeholders). 
Figura 2: Macroprocesso da materialidade

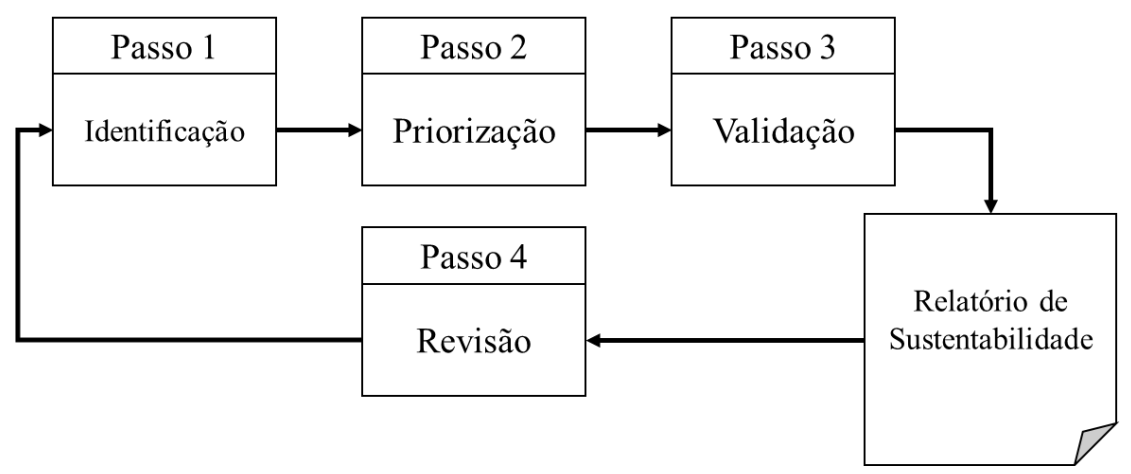

Fonte: Adaptada da GRI (2016, p. 10).

A KPMG (2014) destaca alguns benefícios do processo de materialidade, se aplicado corretamente e com ampla consideração e envolvimento dos stakeholders, como alinhamento da estratégia de negócios com os aspectos socioambientais relevantes, identificação de tendências socioambientais para criação de valor, alocação eficiente dos recursos da empresa para os aspectos socioambientais relevantes, identificação na cadeia de onde a empresa está criando ou reduzindo valor, entre outros. Contudo, existem muitos desafios a serem considerados na operacionalização desse processo, os mais comuns são a dificuldade de envolver todo o público interno (principalmente a alta administração), a complexidade do negócio da empresa (muitos stakeholders e muitos aspectos materiais), lentidão no engajamento dos stakeholders, entre outros.

\subsection{Levantamento dos aspectos materiais}

As empresas globais fabricantes de automóveis, cujos relatórios de sustentabilidade são analisados nessa pesquisa, foram eleitas pelo critério de valor de marca. A escolha desse critério se deu porque a sustentabilidade tem sido adotada nas estratégias de negócios das empresas pelo benefício da melhoria da imagem/reputação (MCKINSEY, 2011; JUNIOR et al, 2011; CLARO; CLARO; AMÂNCIO, 2008; BOSZCZOWSKI, 2010) e essa performance é um dos fatores que compõem o valor da marca de uma organização.

Os valores das marcas das empresas foram obtidos pelo relatório da Brand Finance, uma consultoria com mais de 20 anos dedicada à melhor compreensão das finanças de marketing e que desenvolveu metodologias de avaliação de marca transparentes e acessíveis. A Brand Finance avalia anualmente mais de 3.500 marcas de todos os setores e lugares do mundo (BRAND FINANCE, 2018). As 10 (dez) marcas de fabricantes de automóveis com 
maior valor (em milhões de dólares) no ano de 2017, segundo o relatório, podem ser observadas na Tabela 1.

Tabela 1: Ranking das marcas fabricantes de automóveis com maior valor de mercado em 2017

\begin{tabular}{c|c|c|c}
\hline Ranking & Nome da marca & País de Origem & $\begin{array}{c}\text { Valor da marca (em } \\
\text { milhões de dólares) }\end{array}$ \\
\hline $\mathbf{1}$ & Mercedes-Benz & Alemanha & 43.930 \\
\hline $\mathbf{2}$ & Toyota & Japão & 43.701 \\
\hline $\mathbf{3}$ & BMW & Alemanha & 41.790 \\
\hline $\mathbf{4}$ & Volkswagen & Alemanha & 33.670 \\
\hline $\mathbf{5}$ & Honda & Japão & 22.132 \\
\hline $\mathbf{6}$ & Nissan & Japão & 19.376 \\
\hline $\mathbf{7}$ & Porsche & Alemanha & 19.055 \\
\hline $\mathbf{8}$ & Ford & Estados Unidos & 17.294 \\
\hline $\mathbf{9}$ & Audi & Alemanha & 14.951 \\
\hline $\mathbf{1 0}$ & Chevrolet & Estados Unidos & 12.822 \\
\hline
\end{tabular}

Fonte: Adaptada de Brand Finance (2018).

O Quadro 2 expõe o resultado da busca pelas publicações dos relatórios de sustentabilidade referente ao ano de 2017 das 10 (dez) empresas. Como pode ser observado, todas elas publicaram o relatório de sustentabilidade com referência à 2017, o que totaliza 8 (oito) relatórios como objetos dessa pesquisa, pois a comunicação da sustentabilidade da Volkswagen, Audi e Porsche é feita por um único relatório, o do Grupo Volkswagen.

Quadro 2: Levantamento dos relatórios de sustentabilidade das marcas fabricantes de automóveis de 2017

\begin{tabular}{|c|c|}
\hline Marca & $\begin{array}{c}\text { Relatório de Sustentabilidade (ref. } \\
\text { 2017) }\end{array}$ \\
\hline Mercedes-Benz & Publicado - Daimler Group \\
\hline Toyota & Publicado \\
\hline BMW & Publicado \\
\hline Volkswagen & Publicado - Volkswagen Group \\
\hline Honda & Publicado \\
\hline Nissan & Publicado \\
\hline Porsche & Publicado - Volkswagen Group \\
\hline Ford & Publicado \\
\hline Audi & Publicado - Volkswagen Group \\
\hline Chevrolet & Publicado \\
\hline
\end{tabular}

Fonte: Autoria própria. 
O Quadro 3 é o resultado da busca pelo conteúdo da matriz de materialidade dentro dos relatórios de sustentabilidade das empresas. É importante esclarecer que mesmo que o relatório não apresente a matriz de materialidade, objeto desta análise, isto não significa dizer que o processo de materialidade não ocorreu, como é o caso da Mercedes-Benz e da Volkswagen, Audi e Porsche (Grupo Volkswagen), que relataram que houve o processo de materialidade e que os aspectos materiais se encontram na estratégia de sustentabilidade da empresa. A Toyota e a Nissan relataram aplicar o processo da materialidade apenas para a dimensão ambiental da sustentabilidade e por isso também não serão consideradas para análise dessa pesquisa.

Quadro 3: Levantamento das matrizes de materialidade

\begin{tabular}{|c|c|c|c|c|}
\hline $\begin{array}{c}\text { Nome da } \\
\text { marca }\end{array}$ & $\begin{array}{c}\text { Relatório de } \\
\text { Sustentabilidade } \\
\text { (ref. 2017) } \\
\end{array}$ & \begin{tabular}{|c||} 
Contém a \\
Matriz de \\
Materialidade? \\
\end{tabular} & Eixo horizontal & Eixo vertical \\
\hline Toyota & Publicado & Não & - & - \\
\hline BMW & Publicado & Sim & $\begin{array}{c}\text { Relevância para a } \\
\text { empresa }\end{array}$ & $\begin{array}{l}\text { Relevância para os } \\
\text { stakeholders }\end{array}$ \\
\hline Honda & Publicado & Sim & $\begin{array}{c}\text { Relevância para a } \\
\text { empresa }\end{array}$ & $\begin{array}{c}\text { Relevância para os } \\
\text { stakeholders }\end{array}$ \\
\hline Nissan & Publicado & Não & - & - \\
\hline Ford & Publicado & Sim & $\begin{array}{c}\text { Relevância para a } \\
\text { empresa }\end{array}$ & $\begin{array}{c}\text { Relevância para os } \\
\text { stakeholders }\end{array}$ \\
\hline Chevrolet & Publicado & Sim & $\begin{array}{c}\text { Risco e } \\
\text { oportunidade } \\
\text { para a empresa }\end{array}$ & $\begin{array}{c}\text { Impacto no } \\
\text { desenvolvimento } \\
\text { sustentável para os } \\
\text { stakeholders }\end{array}$ \\
\hline Mercedes-Benz & $\begin{array}{l}\text { Publicado - Daimler } \\
\text { Group }\end{array}$ & Não & - & - \\
\hline $\begin{array}{l}\text { Volkswagen } \\
\text { Porsche } \\
\text { Audi }\end{array}$ & $\begin{array}{c}\text { Publicado - } \\
\text { Volkswagen Group }\end{array}$ & Não & - & - \\
\hline
\end{tabular}

Fonte: Autoria própria.

A Tabela 2 (a seguir) apresenta o quantitativo dos aspectos materiais das matrizes de materialidade da BMW, Chevrolet, Ford e Honda. A Tabela 3 apresenta o quantitativo dos aspectos materiais por dimensão da sustentabilidade e mostra que mais da metade dos aspectos materiais levantados por estas empresas, no ano de 2017, eram de dimensão social (54\%), os de dimensão ambiental representaram 36,8\% enquanto que os de aspectos econômicos representaram apenas $9,2 \%$ do total. 
Tabela 2: Aspectos materiais por empresa

\begin{tabular}{c|c}
\hline Empresa & Aspectos materiais \\
\hline Grupo BMW & 32 \\
\hline General Motors & 16 \\
\hline Ford & 19 \\
\hline Honda & 20 \\
\hline Total & $\mathbf{8 7}$ \\
\hline
\end{tabular}

Fonte: Autoria própria.

Tabela 3: Aspectos materiais por dimensão da sustentabilidade

\begin{tabular}{c|c}
\hline Dimensão & Aspectos materiais \\
\hline Ambiental & $36,8 \%$ \\
\hline Econômico & $9,2 \%$ \\
\hline Social & $54 \%$ \\
\hline Total & $\mathbf{1 0 0 \%}$ \\
\hline
\end{tabular}

Fonte: Autoria própria.

Com o objetivo de identificar o aspecto material mais citado no levantamento, foi necessária a classificação dos aspectos com base no conteúdo da Diretriz G4 e o agrupamento por similaridade dos aspectos que não se classificavam em nenhum conteúdo. A Tabela 4 mostra o resultado da classificação e do agrupamento, são apresentados 31 aspectos materiais e o total de vezes em que eles foram citados.

Tabela 4: Aspectos materiais classificados com base no conteúdo da Diretriz G4 e agrupados por similaridade

\begin{tabular}{c|c|c|c|c|c}
\hline Aspecto material & BMW & Chevrolet & Ford & Honda & Total \\
\hline Emissões & 4 & 2 & 4 & 3 & 13 \\
\hline Mobilidade & 1 & 1 & 1 & 2 & 5 \\
\hline Comunidades Locais & 3 & 1 & 1 & - & 5 \\
\hline Avaliação de Fornecedores & 1 & 1 & 1 & 1 & 4 \\
\hline Direitos Humanos & 1 & 1 & 1 & 1 & 4 \\
\hline Gestão do Capital Humano & 2 & 1 & 1 & - & 4 \\
\hline Biodiversidade & 1 & 1 & 1 & 1 & 4 \\
\hline Desempenho Econômico & 1 & - & 2 & 1 & 4 \\
\hline
\end{tabular}




\begin{tabular}{|c|c|c|c|c|c|}
\hline Aspecto material & BMW & Chevrolet & Ford & Honda & Total \\
\hline Água & 1 & 1 & 1 & 1 & 4 \\
\hline Saúde e Segurança no Trabalho & 1 & - & 1 & 1 & 3 \\
\hline Eficiência de Recursos & 1 & - & - & 2 & 3 \\
\hline Diversidade e Igualdade de Oportunidades & 1 & 1 & - & 1 & 3 \\
\hline Saúde e Segurança do Cliente & 1 & 1 & - & 1 & 3 \\
\hline Eletrificação & 1 & - & - & 1 & 2 \\
\hline Privacidade do Cliente & 1 & - & 1 & - & 2 \\
\hline Materiais & 1 & - & 1 & - & 2 \\
\hline Rotulagem de Produtos e Serviços & 1 & 1 & - & - & 2 \\
\hline Produtos e Serviços & - & 1 & 1 & - & 2 \\
\hline Efluentes e Resíduos & 1 & 1 & - & - & 2 \\
\hline Impactos Econômicos Indiretos & 1 & - & - & 1 & 2 \\
\hline Cidades Sustentáveis & 1 & - & 1 & - & 2 \\
\hline Governança & - & 1 & - & 1 & 2 \\
\hline Inovação e Tecnologia & - & 1 & - & 1 & 2 \\
\hline Práticas de Compra & 1 & - & - & - & 1 \\
\hline Combate à Corrupção & 1 & - & - & - & 1 \\
\hline Treinamento e Educação & 1 & - & - & - & 1 \\
\hline Condução Autônoma & 1 & - & - & - & 1 \\
\hline Políticas Públicas & 1 & - & - & - & 1 \\
\hline Comunicações de Marketing & 1 & - & - & - & 1 \\
\hline Qualidade do Produto & - & - & - & 1 & 1 \\
\hline Ética & - & - & 1 & - & 1 \\
\hline Total Geral & 32 & 16 & 19 & 20 & 87 \\
\hline
\end{tabular}

Fonte: Autoria própria.

Portanto, o resultado da análise apresenta a emissão de Dióxido de Carbono - CO2 como aspecto material mais citado nas matrizes de materialidade das empresas globais fabricantes de automóveis.

A emissão de CO2 tem sido discutida entre os países, desde 1995, com a COP 1 (Conferência das Partes) que aconteceu em Berlim - Alemanha. Em 2015, 195 países se reuniram em Paris - França para a COP21 e, como desdobramento, adotaram o Acordo de Paris, cujo objetivo central era "fortalecer a resposta global à ameaça da mudança do clima e de reforçar a capacidade dos países para lidar com os impactos decorrentes dessas 
mudanças" (MINISTÉRIO DO MEIO AMBIENTE, 2018b). Segue abaixo um trecho extraído do Acordo de Paris:

\begin{abstract}
Enfatizando com grande preocupação a necessidade urgente de resolver a lacuna significativa entre o efeito agregado dos compromissos de mitigação das Partes em termos de emissões anuais globais de gases de efeito estufa até 2020 e as trajetórias das emissões agregadas consistentes com manter o aumento da temperatura média global a menos de $2^{\circ}$ acima dos níveis industriais e promover esforços para limitar o aumento da temperatura a 1,5 ${ }^{\circ} \mathrm{C}$ acima dos níveis pré-industriais (ONU BRASIL, 2015).
\end{abstract}

Apesar da geração de energia ser o setor que mais contribui para emissão de $\mathrm{CO} 2$ no cenário mundial ( $25 \%$ das emissões), as fabricantes de automóveis contribuem tanto para as emissões das indústrias ( $21 \%$ ), com seu processo de fabricação, quanto para a emissão do setor de transporte (14\%), com a emissão dos motores à combustão (IPCC, 2014).

\title{
3.3 A abordagem da emissão de CO2 na indústria automotiva
}

A partir da análise dos relatórios de sustentabilidade do Grupo BMW, General Motors, Ford e Honda é possível observar que a preocupação com as emissões de CO2 se dá em toda a cadeia de valor. A Figura 3 é um exemplo de cadeia de valor da indústria automotiva que é apresentado no Relatório de Sustentabilidade do Grupo BMW.

Figura 3: Cadeia de Valor do Grupo BMW

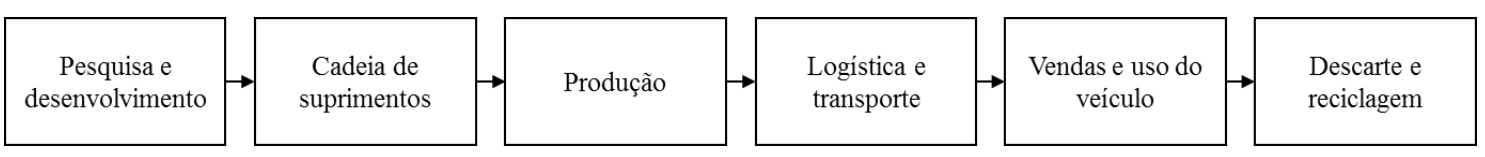

Fonte: Adaptado do GRUPO BMW.

No processo de pesquisa e desenvolvimento, as emissões de CO2 são abordadas através de duas vias principais: investimentos para melhorar a eficiência dos motores de combustão interna e investimentos para realizar a transição dos motores de combustão interna para motores $100 \%$ elétricos (electric vehicles - EV) e híbridos plug-in (plug-in hybrid electric vehicles - PHEV).

Tratar emissões de CO2 na cadeia de suprimentos é um grande desafio para todos os negócios porque envolve uma contribuição voluntária por partes dos fornecedores. A análise dos relatórios de sustentabilidade mostrou que as empresas do setor automotivo têm adotado o CDP Supply Chain Program, um programa projetado para promover o compartilhamento 
de informações e inovação entre as empresas que estão agregando o gerenciamento de emissões de $\mathrm{CO} 2$ da cadeia de suprimento na sua estratégia de sustentabilidade e seus fornecedores de bens e serviços.

Os fornecedores que aceitam o convite das empresas para participar do programa assumem o compromisso de compartilhar com elas seus índices de emissões de CO2. Com essas informações em mãos, as empresas podem traçar metas de redução de emissões para seus fornecedores. Um ponto importante é criar um programa de reconhecimento para os fornecedores que atingem as metas, isso ajuda no engajamento de outros fornecedores nessa iniciativa voluntária.

O processo de produção possui metas claras para redução de emissão de $\mathrm{CO} 2$ focadas no consumo eficiente de energia e energia renovável. A Ford se destaca nesse ponto tendo reduzido 32\% das emissões GEE por veículo produzido entre 2010 e 2017, atingindo a meta de redução com oito anos de antecedência.

Para os processos de logística, que envolvem basicamente o transporte das peças dos fornecedores à fábrica, é abordada a frota interna que realiza o deslocamento de peças e pessoas dentro da fábrica. Para o transporte dos veículos finalizados para os concessionários, as abordagens mostram-se as mais diversas como utilização de carros elétricos para frota interna, caminhões elétricos para entrega dos veículos aos concessionários, definição de um mix de transporte otimizado para redução da quilometragem percorrida, e expansão da preferência por modais de transporte que emitam menos $\mathrm{CO} 2$ como trens e navios para os trajetos de longa distância.

Para vendas e uso do veículo, tem-se os mesmos desafios enfrentados no engajamento dos fornecedores. Algumas empresas se destacam por solicitar requisitos mínimos de sustentabilidade aos seus concessionários, como a redução das emissões das lojas. Outras se destacam por estabelecer programas estruturados de reconhecimento das iniciativas de sustentabilidade dos concessionários, como premiações de projetos de uso de energia renovável.

\section{CONCLUSÃo}

O objetivo geral do trabalho visava analisar os aspectos materiais das Matrizes de Materialidade das empresas globais fabricantes de automóveis, de modo a identificar o aspecto material mais citado e descrever como as empresas o têm abordado. 
Para atingir o objetivo proposto foi necessário explicar o que é a Matriz de Materialidade e sua relação direta com os conceitos de Responsabilidade Social e Sustentabilidade Empresarial e com o movimento do Desenvolvimento Sustentável. Observou-se um grande volume de publicações nas pesquisas sobre o tema. Mas estes temas são complexos, muitas publicações não tinham a qualidade esperada, não apresentavam, por exemplo, a evolução dos conceitos, definições de fontes confiáveis, entre outros problemas, por isso, foi necessário dispor de um tempo considerável para busca das referências. Além disso, tratamos de conceitos que ainda continuam evoluindo, pois são reflexos diretos das relações de trabalho que vêm se modificando cada vez mais com o surgimento de novas tecnologias.

A pesquisa mostrou que o processo de materialidade surgiu como uma ferramenta estratégica para o negócio, pois ao apresentar os aspectos da sustentabilidade mais relevantes para as partes interessadas e qual o impacto desses aspectos nas atividades da empresa, ele possibilita desenhar uma estratégia de sustentabilidade mais alinhada às expectativas dos stakeholders.

Além disso, as empresas criticam a tratativa da sustentabilidade nos seus negócios devido à diversidade e ao grande volume dos aspectos que a temática levanta, relatando ser difícil definir o que é mais importante para ser tratado. Portanto, a Matriz de Materialidade contribui também para o desenho de uma estratégia de sustentabilidade mais efetiva e direcionada.

Os resultados da análise mostraram que, dos dez relatórios de sustentabilidade consultados, apenas quatro divulgaram o conteúdo da Matriz de Materialidade no formato abordado nessa pesquisa. Foram levantados 87 aspectos materiais, dos quais 36,8\% tratavam da dimensão ambiental da sustentabilidade, 9,2\% da dimensão econômica e 54\% da dimensão social. Para identificar o aspecto mais citado foi necessário a classificação com base no conteúdo da Diretriz G4. Aqueles que não se classificavam em nenhum dos conteúdos foram agrupados por similaridade, resultando em 31 aspectos materiais, dos quais a emissão de $\mathrm{CO} 2$ contabilizou o maior volume de citações.

A abordagem das empresas para tratativa do aspecto material de emissão de $\mathrm{CO} 2$ está focada nas emissões da cadeia de valor. As metas mais ambiciosas de redução de emissão de CO2 estabelecidas estão no processo de produção, sendo os fornecedores e os concessionários as partes da cadeia mais difíceis de serem engajadas na temática. Para a redução das emissões de $\mathrm{CO} 2$ na pesquisa e desenvolvimento, a indústria tem trabalhado 
através de duas vias, investimentos para melhorar a eficiência dos motores de combustão interna e investimentos para realizar a transição dos motores de combustão interna para motores 100\% elétricos (electric vehicles - EV) e híbridos plug-in (plug-in hybrid electric vehicles - PHEV), assim como buscar a infraestrutura necessária para a democratização desses tipos de veículos.

Além do seu objetivo inicial, a pesquisa identificou que as empresas estão optando por não divulgar a Matriz de Materialidade nos seus relatórios de sustentabilidade, isso fez com que o volume de dados a serem analisados nesse trabalho diminuísse consideravelmente. Um outro fator desfavorável é a falta de padronização na descrição dos aspectos, o que fez com que fosse necessário agrupar alguns deles por similaridade, de modo a identificar o aspecto mais citado.

Como sugestão de pesquisas futuras tem-se o levantamento das ações de cada empresa no aspecto da emissão de $\mathrm{CO} 2$; a análise das metas de redução de emissões, de modo a verificar se elas contribuem consideravelmente com o Acordo de Paris para não aumentar o aquecimento global em $2^{\circ} \mathrm{C}$, ou se são muito tímidas; e um levantamento das melhores práticas para o engajamento dos fornecedores da indústria automotiva na contribuição da redução das emissões de $\mathrm{CO} 2$.

A Sustentabilidade Empresarial é um caminho que não tem volta. As pesquisas apontam sua contribuição para a reputação da marca, a melhoria dos processos de gestão de riscos, o impacto econômico como resultado da busca pela gestão eficiente dos recursos, e a transparência nas relações com as partes interessadas. Além dos benefícios para a empresa, o Desenvolvimento Sustentável é um movimento em prol da sociedade, que busca a preservação dos "recursos ambientais e culturais para gerações futuras, respeitando a diversidade e promovendo a redução das desigualdades sociais" (INSTITUTO ETHOS, 2009 apud RICO, 2010, p. 8).

\section{REFERÊNCIAS}

ASSOCIAÇÃO BRASILEIRA DE NORMAS TÉCNICAS. NBR ISO 26000: Diretrizes sobre responsabilidade social. Rio de Janeiro, p. 4. 2010. Disponível em: https://edisciplinas.usp.br/pluginfile.php/3203163/mod_folder/content/0/NBRISO26000.pd f?forcedownload=1. Acesso em: 14 abr. 2020. 
ACCOUNTABILITY. AA1000 Accountability Principles Standard. 2008. Disponível em: https://www.accountability.org/wpcontent/uploads/2016/10/AA1000APS_english.pdf. Acesso em: 02 jul. 2018.

BELlantUONO, N; PONTRANDOLFO, P; SCOZZI, B. Capturing the Stakeholders' View in Sustainability Reporting: A Novel Approach. MDPI Sustainability. v. 8, n. 379, p. 12. 2016. Disponível em: https://res.mdpi.com/sustainability/sustainability-0800379/article_deploy/sustainability-08-00379.pdf?filename=\&attachment=1. Acesso em: 02 jul. 2018.

BENITES, L; POLO, E. A sustentabilidade como ferramenta estratégica empresarial: Governança Corporativa e aplicação do Triple Bottom Line na Masisa. Revista de Administração da UFSM, v. 6, Santa Maria, 2013, p. 195-210. Disponível em: https://periodicos.ufsm.br/reaufsm/article/download/8879/pdf. Acesso em: 26 abr. 2020.

BMW GROUP. Sustainable Value Report 2017. Disponível em: https://www.bmwgroup.com/content/dam/bmw-groupwebsites/bmwgroup_com/ir/downloads/en/2017/BMW-Group-SustainableValueReport2017--EN.pdf. Acesso em: 02 jul. 2018.

BRAND FINANCE. Auto \& Tires 2018. Disponível em: https://brandfinance.com/images/upload/brand_finance_auto_tyres_100_report_2018_lock ed.pdf. Acesso em: 02 jul. 2018.

BOSZCZOWSKI, A. K. O engajamento de stakeholders como elemento chave para a estratégia de sustentabilidade corporativa. 2010. p 197. Tese (Mestre em Administração) - Universidade Federal do Paraná, Curitiba, 2010. Disponível em: https://acervodigital.ufpr.br/bitstream/handle/1884/24236/Dissertacao_Engajamento_Stake holders_Anna_Karina_2010.pdf?sequence=1\&isAllowed=y. Acesso em: 02 jul. 2018.

CAMPOS, L M et al. Relatório de sustentabilidade: perfil das organizações brasileiras e estrangeiras segundo o padrão da Global Reporting Initiative. Revista Gestão \& Produção. v.20, n.4, p.913-926. 2013.2 Disponível em: http://www.scielo.br/pdf/gp/v20n4/aop_gp0954_ao.pdf. Acesso em: 02 jul. 2018.

CAVATTI, Felipe. "Relatório de Sustentabilidade" GRI (Global Reporting Initiative) para a Universidade Federal do Espírito Santo: estudo prospectivo sobre possibilidades de adoção. 2014. 142 p. Tese (Mestrado em Gestão Pública) - Universidade Federal do Espírito Santo, Espírito Santo, 2014. Disponível em: http://repositorio.ufes.br/bitstream/10/2497/1/tese_7433_Disserta\%C3\%A7\%C3\%A3o\%20 Final\%20-\%20Felipe\%20Cavatti.pdf. Acesso em: 02 jul. 2018.

CLARO, P; CLARO, D; AMÂNCIO, R. Entendendo o conceito de sustentabilidade nas organizações. Revista de Administração - RAUSP, São Paulo, 2008. Universidade de São Paulo, p. 289-300. Disponível em: http://www.redalyc.org/articulo.oa?id=223417504001. Acesso em: 02 jul. 2018.

CARPEJANI, P; PINHEIRO DE LIMA, E; MACHADO, C. G. O que é materialidade na GRI G4? Uma discussão e agenda para pesquisas futuras. International Workshop Advances in Cleaner Production, ed. 6, São Paulo, 2017. Disponível em: 
http://www.advancesincleanerproduction.net/sixth/files/sessoes/4B/2/carpejani_p_et_al_ac ademic.pdf. Acesso em: 02 jul. 2018.

COMPANHIA ENERGÉTICA DE MINAS GERAIS - CEMIG. Matriz de Materialidade 2017. Disponível em: http://www.cemig.com.br/ras/relatorio2017/Paginas/sobrerelatorio.html. Acesso em: 14 jan. 2019.

DIAS, L. N; SIQUEIRA, J. R; ROSSI, M. Balanço Social: a Utilização dos Indicadores do Global Reporting Initiative (GRI) em Empresas Brasileiras. Encontro Associação Nacional de Pós-Graduação e Pesquisa em Administração, ed. 30, 2006, Salvador, p. 15. Disponível em: http://www.anpad.org.br/admin/pdf/enanpad2006-apsc-0303.pdf. Acesso em: 02 jul. 2018 .

FORD. Sustainability Report 2017/18. Disponível em: https://corporate.ford.com/microsites/sustainability-report-2017-18/doc/sr17.pdf. Acesso em: 02 jul. 2018.

GENERAL MOTORS. 2017 Sustainability Report. Disponível em: https://www.gmsustainability.com/_pdf/downloads/GM_2017_SR.pdf. Acesso em: 02 jul. 2018.

GERHARDT; SILVEIRA, 2009. Métodos de pesquisa. Coordenado pela Universidade Aberta do Brasil - UAB/UFRGS e pelo Curso de Graduação Tecnológica - Planejamento e Gestão para o Desenvolvimento Rural da SEAD/UFRGS. - Porto Alegre: Editora da UFRGS, $2009 . \quad$ Disponível em: http://www.ufrgs.br/cursopgdr/downloadsserie/derad005.pdf. Acesso em: 02 jul. 2018.

GRI, 2002. Diretrizes para relatórios de sustentabilidade. Disponível em: https://www.ethos.org.br/cedoc/diretrizes-para-relatorios-da-sustentabilidade-gri-versao2002/\#.W-cUBHV97IU. Acesso em: 02 jul. 2018.

GRI, 2013. Reporting Principles and Standard Disclosures. Disponível em: https://www.globalreporting.org/resourcelibrary/GRIG4-Part1-Reporting-Principles-andStandard-Disclosures.pdf. Acesso em: 02 jul. 2018.

GRI, 2016. Defining What Matters: Do companies and investors agree on what is material? Disponível em: https://www.globalreporting.org/resourcelibrary/GRIDefiningMateriality2016.pdf Acesso em: 02 jul. 2018.

HONDA. Honda Sustainability Report 2018. Disponível em: https://global.honda/content/dam/site/global/about/cq_img/sustainability/report/pdf/2018/H onda-SR-2018-en-all-02.pdf. Acesso em: 02 jul. 2018.

IPCC, 2014. Summary for Policymakers. In: Climate Change 2014, Mitigation of Climate Change. Disponível em: https://www.ipcc.ch/pdf/assessmentreport/ar5/wg3/ipcc_wg3_ar5_summary-for-policymakers.pdf. Acesso em: 28 nov. 2018.

KPMG. The Essentials of Materiality Assessment. 2014. Disponível em: https://assets.kpmg.com/content/dam/kpmg/cn/pdf/en/2017/the-essentials-of-materialityassessment.pdf. Acesso em: 02 jul. 2018. 
MCKINSEY. The business of sustainability: McKinsey Global Survey results. 2011. Disponível em: https://www.mckinsey.com/business-functions/sustainability-and-resourceproductivity/our-insights/the-business-of-sustainability-mckinsey-global-survey-results. Acesso em: 02 jul. 2018.

MINISTÉRIO DO MEIO AMBIENTE, 2018b. Acordo de Paris. 2018. Disponível em: http://www.mma.gov.br/responsabilidade-socioambiental/agenda-21.html. Acesso em: 02 jul. 2018.

RICO, E. Responsabilidade Social Empresarial e Sustentabilidade. p. 8. 2010. Disponível em: https://revistas.pucsp.br/rad/article/view/2936/1894. Acesso em: 14 abril. 2020.

SPITZECK, H; ÁRABE, M; PEREIRA, N. Guia How-To Matriz de Materialidade: Como priorizar temas socioambientais de acordo com sua relevância para o negócio. Fundação Dom Cabral, p. 20. 2015. Disponível em: https://www.fdc.org.br/conhecimentosite/nucleos-de-pesquisa-site/Materiais/guia_howto_matriz_materialidade.pdf. Acesso em: 02 jul. 2018.

TOYOTA. Sustainability Data Book 2018. Disponível em: https://www.toyotaglobal.com/sustainability/report/archive/sr18/pdf/sdb18_full_en.pdf. Acesso em: 02 jul. 2018.

VOLKSWAGEN. Sustainability Report 2017 Disponível em: https://www.volkswagenag.com/presence/nachhaltigkeit/documents/sustainabilityreport/2017/Nonfinancial_Report_2017_e.pdf. Acesso em: 02 jul. 2018. 